\title{
HUBUNGAN PENGETAHUAN IBU MENYUSUI TENTANG PEMBERIAN ASI DENGAN USIA PENYAPIHAN DI PUSKESMAS PASUNDAN SAMARINDA TAHUN 2017
}

\author{
${ }^{1}$ Imroatus Sholikah ${ }^{2}$ Dwi Riyan Ariestantias ${ }^{3}$ Latifah Nur Rahmadhani ${ }^{4}$ Besse Lidia \\ ${ }^{1}$ Akademi Kebidanan Mutiara Mahakam \\ ${ }^{2}$ Akademi Kebidanan Mutiara Mahakam \\ ${ }^{3}$ Akademi Kebidanan Mutiara Mahakam \\ ${ }^{4}$ Akademi Kebidanan Mutiara Mahakam
}

\begin{abstract}
Abstrak
ASI sebagai makanan alamiah adalah makanan terbaik bagi bayi. ASI juga mengandung zat pelindung yang dapat menghindari bayi dari berbagai penyakit infeksi.Periode pertumbuhan otak yang paling kritis dimulai dari janin sampai anak berusia 2 tahun, apabila pada masa tersebut anak menderita kekurangan gizi dapat berpengaruh negatif terhadap jumlah dan ukuran sel otaknya, dalam hal ini pemberian ASI hingga 2 tahun sangat dianjurkan. Penelitian ini menggunakan adalah analitik korelasional dengan pendekatan cross sectional. Populasi dalam penelitian ini adalah ibu yang mempunyai balita berumur 24 bulan di Puskesmas Pasundan pada bulan Mei-Juni adalah 148 orang dengan jumlah sampel 34 orang dengan menggunakan tekhnik accidental sampling. Pengumpulan data menggunakan kuesioner. Analisis statistik menggunakan uji Chi Square dengan $\alpha=0,05$ Analisa data dalam penelitian ini menggunakan uji statistik dengan menggunakan uji $C h i$ Square diketahui bahwa nilai $\mathrm{p}<\alpha(0,009<0,05)$ dan $\mathrm{X}^{2}$ hitung $>\mathrm{X}^{2}$ tabel $(9,457>5,591)$, dengan demikian artinya ada hubungan antara pengetahuan ibu menyusui tentang pemberian ASI di Puskesmas Pasundan Samarinda tahun 2017.
\end{abstract}

Kata kunci

: pengetahuan, ASI, usia penyapihan

\begin{abstract}
Breastfeeding as a natural food is the best food for babies. Breast milk contains protective substances which can prevent the baby from infectious diseases.. Period of brain growth is most critical of the fetus begins to children aged 2 years, if at the time of the child suffering from malnutrition may negatively affect the number and size of brain cells, in this case breastfeeding is recommended up to 2 years.This study used the analytic cross sectional correlational approachment. The population in this study were mothers who had children aged $\geq \square 24$ months at the health center in May-June are 148 people and samples 34 people by using accidental sampling technique. Data collection using questionnaires. Statistical analysis using Chi Square test with $\alpha=$ 0.05.Analysis of data in this study using a statistical test using Chi Square test is known that the pvalue $<\alpha(0.009<0.05)$ and $X^{2}$ count $>X^{2}$ table $(9.457>5.591)$, thus meaning that there is a relationship between knowledge about breast-feeding mothers breastfeeding in the health center Pasundan Samarinda in 2017.
\end{abstract}

Key words: knowledge, breastmilk, weaning age 


\section{PENDAHULUAN}

Kondisi dari ibu dalam keluarga merupakan penentu kualitas manusia karena ibu di masyarakat adalah penggerak dan pelopor yang berguna untuk peningkatan kesejahteraan keluarga. Ibu adalah penerus generasi keluarga dan bangsa sehingga keberadaan ibu yang sehat jasmani dan rohani serta sosial sangat diperlukan (Depkes, 2005).

Masalah kesehatan dan pertumbuhan anak di Indonesia sangat dipengaruhi oleh keadan gizi yang tidak baik dan merajalelanya penyakit infeksi. Ditemukan di Indonesia bahwa angka kejadian dan kematian karena diare pada tahun 1995 sebanyak 55 ribu balita pertahun. Hal tersebut sering terjadi akibat tidak diberikannya ASI, terbukti anak yang diberi ASI jarang terserang diare (Media Komunikasi Bidan dan Keluarga Indonesia, 2004).Umumnya anak yang tidak memperoleh makanan yang bergizi dalam jumlah yang memadai sangat rentan terhadap penyakit, terutama diare dan Kekurangan Energi Protein (KEP).

Berdasarkan Keputusan Menteri Kesehatan Republik Indonesia Nomor 450/Menkes/SK/IV/2004 bahwa ASI adalah makanan terbaik bagi bayi karena mengandung zat gizi yang paling sesuai untuk pertumbuhan dan perkembangan bayi. ASI perlu diberikan secara eksklusif sampai umur 6 bulan dan dapat dilanjutkan sampai anak berumur 2 tahun. (Depkes, 2005)
ASI sebagai makanan alamiah adalah makanan terbaik yang dapat diberikan oleh seorang ibu kepada anak yang baru dilahirkannya. Selain komposisi yang sesuai untuk pertumbuhan bayi yang bisa berubah sesuai dengan kebutuhan pada setiap saat, ASI juga mengandung zat pelindung yang dapat menghindari bayi dari berbagai penyakit infeksi (Suharyono, 2004).

Pemberian ASI merupakan upaya manusia agar dapat perlindungan namun akhir-akhir ini terutama di kota, banyak para ibu yang melupakan senjata terampuh untuk melindungi anak dari ancaman maut, keadaan ini mungkin disebabkan karena banyak para ibu yang terpaksa bekerja selama sehari penuh untuk menutupi keperluan hidupnya sehari-hari, kemajuan teknologi pembuatan susu buatan dan pengaruh iklan-iklan susu buatan (Suharyono, 2004).

Berdasarkan data Puskesmas Pasundan Samarinda pada tahun 2014 di Kelurahan Jawa terdapat $52,6 \%$ bayi yang mendapatkan ASI eksklusif, dan terdapat 275 bayi usia $\geq$ 24 bulan tetapi masih ada ibu yang tidak memberikan ASI nya sampai 2 tahun.Studi pendahuluan yang dilakukan pada tanggal 29 Maret 2017 oleh peneliti di Puskesmas Pasundan Samarinda dari 10 ibu yang diuji tentang pengetahuan ibu menyusui tentang pemberian ASI didapatkan hasil 30\% berpengetahuan cukup dan $70 \%$ berpengetahuan kurang. Dan berdasarkan hal tersebut penulis tertarik untuk melakukan 
penelitian dengan judul "Hubungan Pengetahuan Ibu Menyusui tentang Pemberian ASI dengan Usia Penyapihan di Puskesmas Pasundan Samarinda”.

\section{METODE PENELITIAN}

Jenis penelitian yang digunakan adalah analitik korelasional dengan pendekatan cross sectional. Analitik korelasional adalah penelitian yang bertujuan untuk mendapatkan gambaran tentang hubungan antara dua variabel penelitian yang kemudian dicari koefisien korelasinya (Suyanto, 2009)

Dalam penelitian ini untuk mengetahui hubungan antara tingkat pengetahuan ibu menyusui dengan usia penyapihan.Metode pengambilan data berdasarkan pendekatan waktu menggunakan cross sectional yaitu metode pengambilan data yang dilakukan pada satu waktu yangsama. Tujuan metode ini agar diperoleh data yang lengkap dalam waktu yangrelatif singkat (Arikunto, 2002).

\section{a. Uji validitas}

Uji validitas ini dapat dilakukan dengan rumus "Pearson Product Moment", setelah itu diuji dengan menggunakan uji t dan lalu dilihat penafsiran dari indeks korelasinya, yaitu:

rhitung $=\frac{\mathrm{n}\left(\sum \mathrm{xy}\right)-\left(\sum \mathrm{x}\right) \cdot\left(\sum \mathrm{y}\right)}{\sqrt{\left\{\mathrm{n} \cdot \sum \mathrm{x}^{2}-\left(\sum \mathrm{x}\right)^{2}\right\} \cdot\left\{\mathrm{n} \cdot \sum \mathrm{y}^{2}-\left(\sum \mathrm{y}\right)^{2}\right\}}}$

Rumus uji t :

$$
\mathrm{t} \text { hitung }=\frac{\mathrm{r} \sqrt{(\mathrm{n}-2)}}{\sqrt{\left(1-\mathrm{r}^{2}\right)}}
$$

Keterangan :

$$
\begin{array}{ll}
\text { r hitung } & : \text { Koefisien Korelasi } \\
\sum \mathrm{X} & : \text { jumlah skor item }
\end{array}
$$

$\sum \mathrm{Y} \quad$ : jumlah skor total (item)

n : jumlah responden

t $\quad$ : nilai t hitung

$\mathrm{r} \quad$ : koefisien korelasi hasil $\mathrm{r}$

hitung

Untuk tabel $\mathrm{t} \alpha=0,05$ derajat kebebasan $(\mathrm{dk}=\mathrm{n}-2)$

Jika nilai $\mathrm{t}$ hitung $>\mathrm{t}$ tabel berarti valid demikian sebaliknya, jika nilai t hitung < ttabel tidak valid (Hidayat, 2010).

b. Uji reliabilitas

Dalam mengukur reliabilitas instrumen yang akan digunakan dalam penelitian ini digunakan teknik uji alpha cronbach dimana kuesioner dikatakan reliabel jika memiki nilai alpha minimal 0,6 (Riyanto, 2010).

Penelitian reliabilitas dalam penelitian ini menggunakan program SPSS versi 18 dan diperoleh nilai alpha $=0,939$. Dengan demikian kuesioner yang digunakan telah reliabel.

\section{HASIL PENELITIAN}

1. Data Umum

Tabel 4.2 Distribusi Frekuensi Umur Responden di Puskesmas Pasundan Samarinda Tahun 2017.

\begin{tabular}{|c|c|c|}
\hline Umur & Frekuensi & Persentase \\
\hline$<20$ Tahun & 3 & $8,8 \%$ \\
$20-35$ & 28 & $82,4 \%$ \\
Tahun & & \\
$>35$ Tahun & 3 & $8,8 \%$ \\
\hline Jumlah & 34 & $100,0 \%$ \\
\hline \multicolumn{2}{|c|}{ Sumber : Data Primer 2017 } \\
\hline
\end{tabular}

Sumber : Data Primer 2017 
Gambar 4.1

$\begin{gathered}\text { Distribusi Frekuensi Umur } \\ \text { Responden }\end{gathered}$
$\square 20$ tahun $\quad 20-35$ tahun
$>35$ tahun
$8,8 \%$
82,4
$\%$

Berdasarkan tabel dan diagram diatas didapatkan bahwa sebagian besar responden berumur 20-35 tahun sebanyak 28 responden $(82,4 \%)$, sementara yang berumur kurang dari 20 tahun sebanyak 3 responden $(8,8 \%)$ dan yang berumur lebih dari 35 tahun sebanyak 3 responden $(8,8 \%)$.

Tabel 4.3 Distribusi Frekuensi Pendidikan Responden di Puskesmas Pasundan Samarinda Tahun 2017

\begin{tabular}{|c|c|c|}
\hline Pendidikan & Frekuensi & Persentase \\
\hline SD & 4 & $11,8 \%$ \\
SMP & 7 & $20,6 \%$ \\
SMA & 20 & $58,8 \%$ \\
PT & 3 & $8,8 \%$ \\
\hline Jumlah & 34 & $100,0 \%$ \\
\hline
\end{tabular}

Sumber : Data Primer 2017

Gambar 4.2

\section{Distribusi Frekuensi Pendidikan Responden}

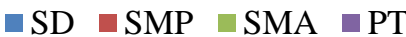

$8,8 \%$

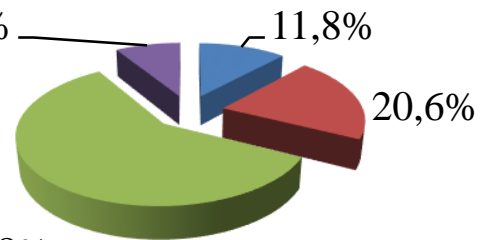

$58,8 \%$
Berdasarkan tabel dan diagram diatas didapatkan bahwa sebagian besar responden dengan pendidikan terakhir SMA yaitu sebanyak 20 responden $(58,8 \%)$, SMP sebanyak 7 responden (20,6\%), SD sebanyak 4 responden $(11,8 \%)$, dan perguruan tinggi sebanyak 3 responden $(8,8 \%)$.

Tabel 4.4 Distribusi Frekuensi Pekerjaan Responden di Puskesmas Pasundan Samarinda Tahun 2017

\begin{tabular}{|c|c|c|}
\hline Pekerjaan & Frekuensi & Persentase \\
\hline Bekerja & 30 & $88,2 \%$ \\
$\begin{array}{c}\text { Tidak } \\
\text { bekerja }\end{array}$ & 4 & $11,8 \%$ \\
\hline Jumlah & 34 & $100,0 \%$ \\
\hline \multicolumn{2}{|c|}{ Sumber : Data Primer 2017 }
\end{tabular}

Gambar 4.3

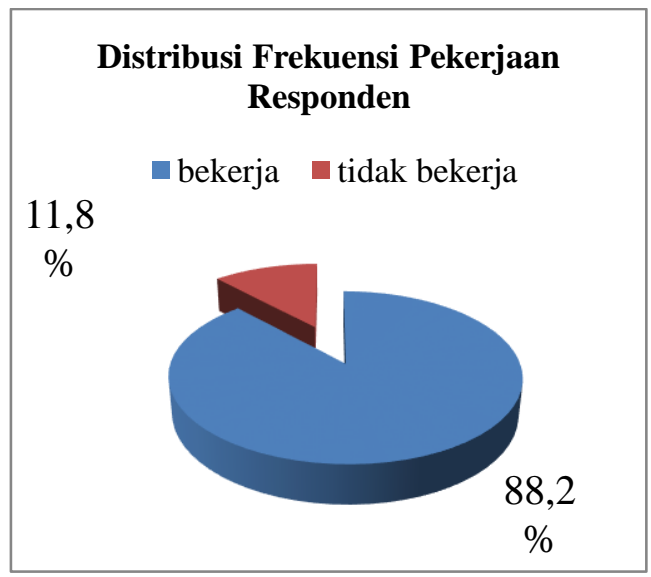

Berdasarkan tabel dan diagram diatas didapatkan bahwa sebagian besar responden sebagai bekerja yaitu sebanyak 30 responden $(88,2 \%)$ dan responden yang tidak bekerja di luar rumah sebanyak 4 responden $(11,8 \%)$. 
2. Analisa Univariat

a. Variabel Independen

Variabel independen dalam penelitian ini adalah pengetahuan ibu menyusui tentang pemberian ASI di Puskesmas Pasundan Samarinda tahun 2017.

Tabel 4.5 Distribusi Frekuensi Responden Untuk Pengetahuan ibu menyusui tentang ASI di Puskesmas Pasundan Samarinda 2017

\begin{tabular}{|c|c|c|}
\hline Pengetahuan & Frekuensi & Persentase \\
\hline Baik & 3 & $8,8 \%$ \\
Cukup & 11 & $32,4 \%$ \\
Kurang & 20 & $58,8 \%$ \\
\hline Jumlah & 34 & $100,0 \%$ \\
\hline
\end{tabular}

Sumber : Data Primer 2017

\section{Gambar 4.4}

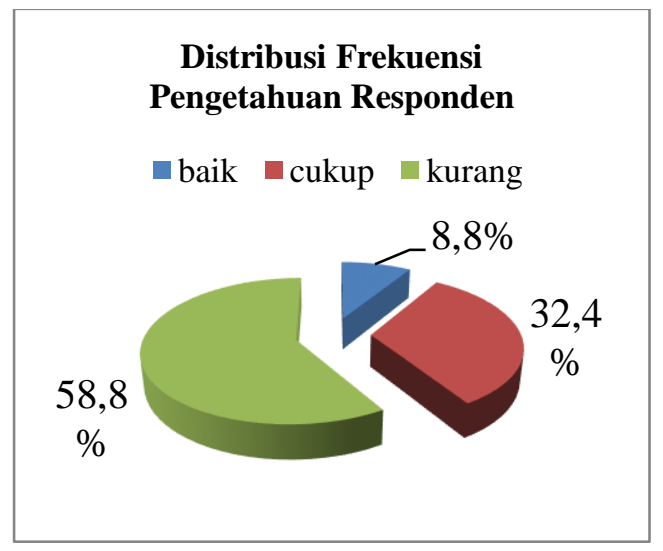

Berdasarkan tabel dan diagram diatas didapatkan pengetahuan yang kurang tentang pemberian ASI yaitu sebanyak 20 responden $(58,8 \%)$, pengetahuan cukup sebanyak 11 responden $(32,4 \%)$, dan pengetahuan baik sebanyak 3 responden $(8,8 \%)$.

b. Variabel Dependen
Variabel Dependen dalam penelitian ini adalah Usia penyapihan di Puskesmas Pasundan Samarinda Tahun 2017

Tabel 4.6 distribusi frekuensi responden untuk usia penyapihan di puskesmas pasundan Samarinda tahun 2017

\begin{tabular}{|c|c|c|}
\hline Perilaku & Frekuensi & Persentase \\
\hline 2 tahun & 10 & $29,4 \%$ \\
$<2$ & 24 & $70,6 \%$ \\
tahun & & \\
\hline Jumlah & 34 & $100,0 \%$ \\
\hline
\end{tabular}

\section{Gambar 4.5}

\section{Distribusi Frekuensi Usia Penyapihan}

$$
\square<2 \text { tahun } \square 2 \text { tahun }
$$

$29,4 \%$

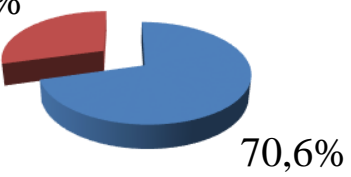

Berdasarkan tabel dan diagram diatas didapatkan sebagian besar responden dengan usia penyapihan kurang dari 2 tahun yaitu sebanyak 24 responden $(70,6 \%)$ dan responden dengan usia penyapihan 2 tahun sebanyak 10 responden $(29,4 \%)$.

\section{Analisa Bivariat}

Setelah melakukan analisa bivariat, selanjutnya dilakukan analisa bivariat untuk mengetahui apakah ada hubungan antara pengetahuan ibu menyusui tentang pemberian ASI dengan usia penyapihan di Puskesmas Pasundan Samarinda tahun 2017. 
Tabel 4.6 Hubungan pengetahuan ibu menyusui tentang pemberian ASI dengan usia penyapihan di Puskesmas Pasundan Samarinda Tahun 2017.

\begin{tabular}{|c|c|c|c|c|c|c|c|}
\hline \multirow{3}{*}{$\begin{array}{c}\text { Pengeta } \\
\text { huan }\end{array}$} & \multicolumn{4}{|c|}{ Usia penyapihan } & \multirow{2}{*}{\multicolumn{2}{|c|}{ Total }} & \\
\hline & \multicolumn{2}{|c|}{$\begin{array}{c}2 \\
\text { tahun }\end{array}$} & \multicolumn{2}{|c|}{$\begin{array}{l}<2 \\
\text { tahun }\end{array}$} & & & val \\
\hline & $n$ & $\%$ & $\mathrm{n}$ & $\%$ & $\mathrm{n}$ & $\%$ & \\
\hline Baik & 3 & 8, & 0 & $\begin{array}{c}0 \\
20\end{array}$ & 3 & $\begin{array}{l}8,8 \\
32,\end{array}$ & 0,0 \\
\hline Cukup & 4 & 8 , & 1 & $\begin{array}{r}6 \\
50 \\
, 0\end{array}$ & 2 & $\begin{array}{c}4 \\
58 \\
8\end{array}$ & 09 \\
\hline Total & 1 & 29 & 2 & $\begin{array}{r}70 \\
, 6\end{array}$ & 3 & $\begin{array}{c}100 \\
, 0\end{array}$ & \\
\hline
\end{tabular}

Sumber : Data Primer 2017

Berdasarkan tabel diatas hasil analisis hubungan pengetahuan ibu menyusui tentang pemberian ASI dengan usia penyapihan di Puskesmas Pasundan Samarinda diperoleh bahwa dari 34 responden, terdapat 3 responden dengan pengetahuan baik dan juga menyapih bayinya pada usia sampai 2 tahun, sedangkan 11 responden dengan pengetahuan cukup, 7 diantaranya memiliki menyapih bayinya kurang dari 2 tahun. Dan 4 responden lainnya menyapih bayinya sampai usia 2 tahun, sementara responden dengan pengetahuan kurang sebanyak 20 responden dengan 17 responden diantaranya menyapih kurang dari 2 tahun dan 3 responden lainnya menyapih sampai usia sampai 2 tahun.
Berdasarkan uji statistik diperoleh hasil nilai $\mathrm{P}$ value $=0,009$ dengan $\alpha=0,05$ dan $\mathrm{X}^{2}$ hitung $=9,457$ dengan $X^{2}$ tabel $=5,591$ maka dapat dilihat bahwa $\mathrm{P}$ value $<\alpha(0,009<$ 0,05) dan $X^{2}$ hitung > $X^{2}$ tabel $(9,457>$ 5,591), dengan demikian Ho ditolak dan $\mathrm{Ha}$ diterima artinya ada hubungan antara pengetahuan ibu menyusui tentang pemberian ASI di Puskesmas Pasundan Samarinda tahun 2017.

\section{PEMBAHASAN}

1. Pengetahuan tentang pemberian ASI di Puskesmas Pasundan Samarinda

Pengetahuan adalah hasil "tahu", dan ini terjadi setelah orang melakukan pengindraan terhadap suatu objek tertentu. Hasil penelitian yang dilakukan menunjukkan bahwa dari 34 responden, terdapat 20 responden $(58,8 \%)$ yang pengetahuannya kurang tentang pemberian ASI, ini mungkin dikarenakan ibu mempunyai sumber informasi yang kurang. Penelitian ini juga didapatkan pengetahuan yang cukup sebanyak 11 responden $(32,4 \%)$, dan pengetahuan baik sebanyak 3 responden $(8,8 \%)$.

Menurut Latipun (2006), bahwa orang dewasa cenderung mendapatkan pengetahuan dari pengalamannya. Pekerjaan merupakan kegiatan utama yang dilakukan untuk mencari nafkah. Lingkungan pekerjaan dapat digunakan sebagai sarana dalam mendapatkan informasi yaitu dengan bertukar pikiran dengan teman-teman di lingkungan kerja. 
Hal ini sesuai dengan pendapat Kuncoroningrat yang dikutip oleh Nursalam dan Pariani (2003), yaitu lingkungan adalah seluruh kondisi yang ada di sekitar manusia dan pengaruhnya dapat mempengaruhi perkembangan pengetahuan dan perilaku orang atau kelompok.

Menurut Kuncoroningrat yang dikutip oleh Nursalam dan Pariani (2003), bahwa pendidikan seseorang berpengaruh pada pengetahuannya dimana semakin tinggi tingkat pendidikan seseorang makin banyak pula pengetahuan yang dimiliki. Sebaliknya, pendidikan yang rendah atau kurang akan menghambat perkembangan sikap seseorang terhadap nilai baru yang diperkenalkan sehingga pengetahuan juga kurang.

\section{Usia Penyapihan di Puskesmas}

Pasundan Samarinda

$$
\text { Menurut Notoadmojo }
$$
pengetahuan adalah upaya memberi pengetahuan sehingga terjadi perubahan yang meningkat. Sedangkan Menyapih (weaning) adalah suatu proses berhentinya masa menyusui yang dapat dilakukan secara bertahap atau seketika. Proses menyapih dapat disebabkan oleh berhentinya sang anak menyusu pada ibunya atau bisa juga sang ibu yang berhenti menyusui anaknya.

Kurangnya penyapihan sampai 2 tahun ini mungkin juga dikarenakan kurangnya waktu dalam melakukan penyapihan karena sebagian besar ibu yang menyusui adalah bekerja, dukungan dari tenaga kesehatan juga sangat penting dalam memberikan penyuluhan tentang penyapihan karena status gizi anak usia sampai 2 tahun sangat menentukan pertumbuhan anak.

Penelitian yang dilakukan Rif'ah Nur (2004), menyatakan bahwa ada hubungan yang signifikan antara lama pemberian ASI dengan status gizi anak usia 4-24 bulan. Pemberian ASI yang diberikan dalam usia anak yang lebih dini akan mempengaruhi pertumbuhan anak karena usia masa bayi mulai disapih adalah masa-masa rawan gizi (2004).

3. Hubungan Pengetahuan Ibu Menyusui Tentang Pemberian ASI dengan Usia Penyapihan di Puskesmas Sidomulyo Samarinda Tahun 2017

Hasil penelitian menunjukkan bahwa hanya sebagian kecil responden memiliki pengetahuan yang baik tentang pemberian ASI, hal ini sesuai dengan proporsi responden dengan melakukan penyapihan dimana responden menyapih bayinya sampai usia 2 tahun. Hal ini menunjukkan bahwa responden yang pengetahuan tentang pemberian ASInya baik akan menyapih bayinya sampai usia 2 tahun, demikian sebaliknya responden yang pengetahuan tentang pemberian ASInya kurang akan menyapih dengan usia kurang dari 2 tahun pula.

Hal ini kemungkinan disebabkan karena kurangnya informasi tentang pentingnya pemberian ASI pada anak sampai usia 2 tahun. Dan juga mungkin dipengaruhi karena pendidikan responden dimana semakin tinggi pendidikan seseorang maka semakin baik pengetahuan dan penyapihannya. 
Dari hasil uji statistik diperoleh hasil nilai $\mathrm{P}$ value $=0,009$ dengan $\alpha=0,05$ dan $\mathrm{X}^{2}$ hitung $=9,457$ dengan $X^{2}$ tabel $=5,591$ maka dapat dilihat bahwa $\mathrm{P}$ value $<\alpha(0,009<$ 0,05) dan $X^{2}$ hitung $>X^{2}$ tabel $(9,457>$ 5,591) berarti terdapat hubungan antara pengetahuan ibu menyusui tentang pemberian ASI dengan usia penyapihan di Puskesmas Pasundan Samarinda tahun 2017.

Berdasarkan hasil penelitian yang telah dilakukan ini, diharapkan tenaga kesehatan dapat terus meningkatkan pengetahuan dan dapat memberikan penyuluhan kepada ibu yang menyusui dalam memberikan ASI dan dapat melakukan penyapihan yang baik pada anaknya sampai usia 2 tahun.

\section{KESIMPULAN}

Berdasarkan hasil penelitian dan pembahasan, ada beberapa hal yang dapat di simpulkan yaitu sebagai berikut :

1. Ada hubungan antara pengetahuan ibu menyusui tentang pemberian ASI dengan usia penyapihan di Puskesmas Pasundan Samarinda tahun 2017.

2. Pengetahuan ibu menyusui tentang pemberian ASI di Puskesmas Pasundan Samarinda tahun 2017 yaitu sebanyak 58,8\% dengan pengetahuan kurang, 32,4\% dengan pengetahuan cukup, dan $8,8 \%$ yang memiliki pengetahuan baik.

3. Usia penyapihan pada anak di Puskesmas Pasundan yang usia penyapihannya kurang dari 2 tahun yaitu sebanyak 70,6\% dan yang usia penyapihan sampai 2 tahun sebanyak $29,4 \%$.
4. Ada hubungan antara pengetahuan ibu menyusui tentang pemberian ASI dengan usia penyapihan di Puskesmas Pasundan Samarinda tahun 2017 yang dilihat dari hasil uji statistik yang menunjukkan bahwa $P$ value $<\alpha(0,009<0,05)$ dan $\mathrm{X}^{2}$ hitung $>\mathrm{X}^{2}$ tabel $(9,457>5,591)$.

\section{DAFTAR PUSTAKA}

Arikunto,S. 2002. Prosedur penelitian dan pendekatan praktek. Edisi V. Jakarta : Rineka/Cipta 2006. Manajemen Penelitian. Jakarta : Rineka cipta 2010. Prosedur Penelitian Suatu Pendekatan Praktik. Jakarta : Rineka cipta

Asyadhad, Amalia. 2006. Makanan Tepat Untuk Balita. Jakarta : Kawan Pustaka.

Atikah.P. 2010. Kapita Selekta ASI dan Menyusui. Yogyakarta : Medical book

Azwar Asrul. 2005. Manajemen Laktasi.Jakarta : Depkes RI

Depkes RI. 2006. Profil Kesehatan Indonesia. Jakarta

Hidayat, Aziz Alimul. 2007. Metode Penelitian Kebidanan \& Teknik Analisis Data. Jakarta : Salemba Medika 
2010. Metode Penelitian Kebidanan \& Teknik Analisis Data. Jakarta : Salemba Medika

http://j3ffunk.blogspot.com/2011/08/alasanibu-melakukan-penyapihan-anak.html, di akses pada tanggal 16 maret 2012 http://kuliahbidan.wordpress.com/ diakses pada tanggal 16 maret 2012

Karen, Hogg dkk. 2005. Menyusui Cara Mudah, Praktis dan Nyaman. Jakarta : Arcan.

Nadesul, Hendrawa.2004. Makanan Sehat Untuk Bayi. Jakarta : Puspa Swara.

Nugroho,Taufan. 2011. Asi dan Tumor Payudara. Yogyakarta: Nuha Medika

Nursalam, \& Siti Pariani. 2003. Pendekatan Praktis Metodologi Riset Keperawatan. Jakarta : CV Sagung Seto

Notoadmodjo. 2002. Metodologi Ilmu Keperawatan. Jakarta : Salemba Medika

2003. Ilmu Kesehatan Maasyarakat, Cetakan Kedua. Jakarta : Rineka Cipta

2001. Pendekatan Praktis
Metodologi
Keperawatan.Jakarta : Rineka Cipta
. 2005. Metodologi Penelitian
Kesehatan.Jakarta : Rineka Cipta

Riduwan. 2005. Dasar-Dasar Statistika. Bandung : Alfabeta

Riyanto, Agus. 2010. Pengolahan dan Analisis Data Kesehatan. Jogjakarta : Ruha Medika

Roesli, Utami. 2004. Mengenal ASI Eksklusif. Jakarta : EGC

Santosa, Erina. 2004. Menyusui Bayi. Jakarta : progres.

Setiawan, Ari, dan Saryono. 2010. Metodologi Penelitian Kebidanan DIII, DIV, SI, dan S2. Yogyakarta : Ruha Medika

Soetjiningsih, 2002. ASI Petunjuk untuk Tenaga Kesehatan. Jakarta : EGC 
JURNAL KEBIDANAN MUTIARA MAHAKAM, VOLUME VI NOMOR 2, SEPTEMBER 2018 